\title{
Should Dentists be Allowed to Administer Botulinum Toxin?
}

\author{
Brion Benninger ${ }^{1,2,3 *}$ and Alan Ross $s^{1,2,3}$
}

${ }^{1}$ Departments of Medical Anatomical Sciences, College of Dental Medicine, Western University of Health Sciences, Lebanon

${ }^{2}$ College of Dental Medicine, Western University of Health Sciences. Samaritan Health Services, Orthopaedic and General Surgery Residency Faculty, Lebanon \&

Corvallis

${ }^{3}$ Departments of Oral Maxillofacial Surgery, Surgery, and Orthopaedic Surgery. Oregon Health \& Science University, Portland

\begin{abstract}
Purpose: The purpose of this study was to investigate why dentists should be allowed to administer botulinum toxin (BoNTA). There are several common pathologies that occur in dentistry that BoNTA could be used to alleviate.

Introduction: Pathology resulting from improper clenching and impact force by muscles of mastication are significant issues faced by dentists. Many techniques used for the treatment of these pathologies are expensive, invasive for the patient, and may be ineffective. BoNTA inhibits acetylcholine release, blocking or reducing the contraction of muscles which can have a positive outcome for patients with increased muscle spasm, temporomandibular joint pathologies, bruxism, trismus, tolerance of intra-oral prostheses and other oral conditions.
\end{abstract}

Methods: A literature search of texts, journals and websites was conducted for BoNTA and its use in dentistry. We analyzed the basic science and clinical curriculum of 20 dental and medical healthcare training institutions.

Results: Today's dentists are prepared to administer BoNTA because of their extensive head and neck anatomical training, pharmacology and the experience acquired from thousands of clinical injections.

Conclusion: Currently, the American Dental Association has not taken a position on the administration of BoNTA by dentists; however, several Dental State Boards have developed, or are developing a policy for its use. This study proposes that dentists should be allowed to inject BoNTA based on their didactic and clinical anatomy courses and clinical curriculum. BoNTA is an effective treatment for oral pathologies.

\section{Introduction}

The botulinum toxin (BoNTA) was first conceived for medical and therapeutic uses by a German physician Justinus Kerner (1786-1862) [1]. In 1895, the bacterium was isolated by Emile Van Ermengem. It wasn't until 1944 when the toxin was finally isolated. The toxins' high affinity for cholinergic nerve terminals decreases the release of acetylcholine, resulting in muscle paralysis. There are seven serotypes (A-G) of the toxin and each responds to a unique antibody. In 1973, Alan B.Scott found clinical use for the temporary paralysis of musculature and located the mechanism that furthered its development for therapeutic use. BTX-A (BoNTA) is the most commonly used and has less pain associated with the injection, and has a slower onset of action with longer paralysis. In 1989, BoNTA was approved for strabismus, blepharospasm, and hemifacial spasm. In 2000, BTX-B (Myobloc) was approved by the FDA for cervical dystonia. BTX-E and BTX-F is used only for those individuals who are resistant to $\mathrm{A}$ and $\mathrm{B}$ due to clinical resistance or antibody formation. In 2002, BoNTA was approved by the FDA for temporary treatment of glabellar lines ${ }^{1}$. There are no absolute contraindications; however, there are relative contraindications including, pregnant/lactating women, less than 12 years old, neurovascular disease and previous reaction. (onabotuliumtoxinA or Botulitum toxin type A). In adults, Botox is FDA approved for: 1) Blepharospasm, 2) Cervical dystonia, 3) Focal spasticity, 4) Chronic migrane, 5) Strabismus and 6) various cosmetic (reducing lines or 'wrinkles'). In children, it is primarily used for the first three conditions of dystonia. It did receive a Black Box warning in 2009 by the FDA for the ability to migrate from injection site (systemic toxicity) that could lead to life-threatening symptoms of botulinism (dysphagia and breathing difficulties). This is more likely to occur after IM injection to treat the conditions of dystonia (especially children) vs. cosmetic indications. Other common symptoms include: hypersenstivity or anaphylaxis (due to fact that it is a protein) and reduced local sweating. Use with caution in patients with bleeding disorder or receiving anticoagulants (e.g., coumadin). Adverse effects usually occur in 1 week and may last up to several months, but this primarily following IM injections not after cosmetic injections $(1 / 2$ dose of IM preparations) [2,3].

BoNTA is most commonly thought of as a therapy for achieving cosmetic results, but the therapeutic uses extend far beyond cosmetic applications, including facial dystonias, spasticity, salivary flow, nondystonic disorder of involuntary muscle activity, smooth muscle hyperactive disorders, sweating disorders, fistula treatment and temporomandibular discomfort [4-20]. According to the National Institute of Dental and Craniofacial Research, there is an estimated 10 million people who suffer from TMJ or TMJ related chronic pain. Within this group, there is an increase in the younger population revealing symptoms, thus indicating an increase of TMJ chronic pain in the future [21] (Table 1)

Who in the healthcare profession (medical and/or dental) should be given the privileges to inject BoNTA? Moreover, is there an area of healthcare that specifically prepares a clinician to safely administer injections to the head and neck region? We will demonstrate that a contemporary trained dentist is qualified to administer BoNTA.

*Corresponding author: Brion Benninger, Western University of Health Sciences, COMP-Northwest, 200 Mullins Way, Lebanon, E-mail: bbenninger@westernu.edu; benninge@ohsu.edu

Received March 29, 2012; Accepted May 15, 2012; Published May 20, 2012

Citation: Benninger B, Ross A (2012) Should Dentists be Allowed to Administer Botulinum Toxin? Dentistry 2:135. doi:10.4172/2161-1122.1000135

Copyright: (c) 2012 Benninger B, et al. This is an open-access article distributed under the terms of the Creative Commons Attribution License, which permits unrestricted use, distribution, and reproduction in any medium, provided the original author and source are credited. 


\section{Methods}

A literature search of texts, journals and websites was conducted for BoNTA and its use in dentistry. PubMed was initiatlly used for the literature search, and this was followed up with a literature search using Google Scholar. The specific terms search were "botulinum toxin," "botox," "dentistry and botox," "head, face and botox," "oral maxillofacial surgery and botox." We analyzed the basic science and clinical curriculum of 20 dental and medical healthcare training institutions, which were chosen at random. There was no funding for this study.

\section{Results}

Textbooks and journal articles revealed multiple uses for BoNTA therapy in treating intra and extra oral pathologies. Results from investigating basic science curriculum and clinical skill instruction, revealed excellent practice, and suggested that dental training safely prepared trainees to administer BoNTA. Generally, dentists receive an accelerated clinical anatomy course below the head and neck and an 11 to 12 week specific course of head and neck anatomy compared to their medical colleagues who receive on average 2 to 3 weeks of head and neck anatomy education during their first 4 years of prequalification training. A contemporary trained general dentist delivers between 3,000 and 4,000 injections at multiple sites intra and extra orally during 4 years of prequalification training. During the first 4 years of medical training, a medical student will give less than 50 injections, which are usually given into large joints or to laceration edges for sutures. In a 3-year or 4-year medical resident training program (family practice, internal medicine, surgical specialties) residents administer considerably less than 3000 to 4000 injections. Both medical and dental students receive comprehensive pharmacology and physiology courses. Many clinical training institutions provide yearly resuscitation courses to maintain updated certifications (Table 2).

\section{Discussion}

Historically, many of the neuromuscular pathologies presented to general dentists have been treated surgically by medical physicians, which included oral maxillofacial specialists. BoNTA has proven to be an effective method for therapeutic treatment of many pathologies intra and extra orally.

Botox has been used by head and neck clinicians to treat migraine headaches (Binder et al). Using Botox as part of the arsenal for a dentist

\begin{tabular}{|c|l|l|}
\hline $\begin{array}{l}\text { Pathologies of the Head and Neck region Benefit from BoNTA Injections } \\
\text { Therapeutic }\end{array}$ \\
\hline 1 & $\begin{array}{l}\text { Tempromandibular } \\
\text { Joint Discomfort }\end{array}$ & $\begin{array}{l}\text { National Institute of Dental and Craniofacial Research } \\
\text { estimates } 10.8 \text { million people will suffer from TMJ } \\
\text { discomfort }\end{array}$ \\
\hline 2 & $\begin{array}{l}\text { Dystonia/ } \\
\text { Hyperactive Lip }\end{array}$ & $\begin{array}{l}\text { Abnormal tonicity of muscle resulting in repetitive } \\
\text { muscle Contractions that may cause twisting or } \\
\text { jerking. }\end{array}$ \\
\hline 3 & $\begin{array}{l}\text { Post Surgical } \\
\text { Solving Fistula }\end{array}$ & $\begin{array}{l}\text { An abnormal duct or passage resulting from injury, } \\
\text { disease, or a congenital disorder that connects an } \\
\text { abscess, cavity, or hollow organ to the body surface }\end{array}$ \\
\hline 4 & Frey's Syndrome & $\begin{array}{l}\text { Redness and sweating on the cheek area adjacent to } \\
\text { the ear }\end{array}$ \\
\hline 5 & Bruxism & Clenching and grinding the teeth \\
\hline 6 & Smile aesthetics & Cervical accidents \\
\hline 7 & Intra oral Devices & To allow compliance \\
\hline
\end{tabular}

Table 1: Head \& Neck Pathologies and Botox Treatment.

\begin{tabular}{|c|c|c|}
\hline \multicolumn{3}{|c|}{ Clinical Anatomy - Head \& Neck Instruction } \\
\hline Schools & Dental & Medical \\
\hline 1 & 11 wks & 2 wks \\
\hline 2 & $8 w k s$ & $3 w k s$ \\
\hline 3 & $8 w k s$ & $3 w k s$ \\
\hline 4 & $11 w k s$ & $2 w k s$ \\
\hline 5 & $11 w k s$ & $2 w k s$ \\
\hline 6 & $12 w k s$ & $4 w k s$ \\
\hline 7 & $9 w k s$ & $3 w k s$ \\
\hline 8 & $11 w k s$ & $2 w k s$ \\
\hline 9 & $11 w k s$ & $2 w k s$ \\
\hline 10 & $11 w k s$ & $3 w k s$ \\
\hline
\end{tabular}

Table 2: Time Allocated for Didactic Anatomy Instruction.

would include treatment of headaches or migraines when related to TMD. Therefore, being aware of the classically described sites to inject Botox for migraines would be advantageous: 1. Glabella, 2. Temporal, 3. Forehead Temporal, 4. Forehead, 5. Occipital, and 6. Suboccipital. The drawback for dentists to treat headaches is that they do not receive training about signs, symptoms and differential diagnosis of brain tumors or space occupying lesions. If the headache is due to TMD, they could use Botox to treat accordingly. Implants and other surgical procedures can aid the integrity of the intraoral architecture and maintain the orientation of hard and soft tissues. BoNTA can be administered for extra oral aesthetics to compliment one's oral-to-face relationships. A compromise would be to allow the general dentist to provide BoNTA injections limited by anatomical boundaries. The authors suggest that injections are limited to the neck and face at or below the infra orbital rims and temporal regions.

There doesn't appear to be an obvious set of criteria within the healthcare profession to determine who can administer BoNTA injections. The results of this study revealed that a dentally trained clinician has appropriate knowledge and training in the basic sciences and clinical skills compared to contemporary medically trained physicians, which enable them to administer BoNTA injections safely. In order to police a high standard of care and safety, governing boards that decide on which healthcare providers are allowed privileges to administer BoNTA injections could demand regular continuing dental/medical education courses. This would ensure safe treatment to patients and maintain high delivery standards by updating the clinician's basic science knowledge and clinical skill level. Dental trainees receive more didactic training of the head and neck region and develop a more extensive repertoire of injection techniques during their training compared to contemporary medical school trainees. Specialty clinics, such as Oral Maxillofacial surgery, are being inundated by patients presenting with facial pain generally treated with BoNTA therapy. Many Oral Maxillofacial surgeons would be grateful if the responsibility for BoNTA injection was shared with their general dentist colleagues. This would allow Oral Maxillofacial surgeons to see potential surgical conditions in a more timely manner, thus better utilizing their specialized training.

\section{Conclusion}

This study revealed the training of a general dentist appears to satisfy the basic science knowledge and clinical skills one would need to administer BoNTA injections to the head and neck region. 


\section{References}

1. Erbguth FJ (2004) Historical notes on botulism, Clostridium botulinum, botulinum toxin, and the idea of the therapeutic use of the toxin. Mov Disord 19: S2-S6.

2. Tan EK, Jankovic J (2000) Treating severe Bruxism with botulinum toxin. J Am Dent Assoc 131: 211-216.

3. Tan EK, Jankovic J (1999) Botulinum toxin A in patients with oromandibular dystonia:long-term follow-up. Neurology 53: 2102-2107.

4. Laskawi, R., Rohrbach S (2001) Oromandibular dystonia. Clinical forms, diagnosis and examples of therapy with botulinum toxin. Laryngorhinootologie 80: 708-713.

5. Clark GT (2003) The management of oromandibular motor disorders and facial spasms with injections of botulinum toxin. Phys Med Rehabil Clin N Am 14: 727-748.

6. Ellies M, Gottstein U, Rohrbach-Volland S, Arglebe C, Laskawi R (2004) Reduction of salivary flow with botulinum toxin: extended report on 33 patients with drooling, salivary fistulas and sialadenitis. Laryngoscope 114: 1856-1860.

7. Ellies M, Laskawi R, Rohrbach-Volland S, Arglebe C, Beuche W (2002) Botulinum toxin to reduce saliva flow: selected indications for ultrasoundguided toxin application into salivary glands. Laryngoscope 112: 82-86.

8. Katz H (2005) Botulinum toxins in dentistry- the new paradigm for masticatory muscle hypoertonicity. Singapore Dent J 27: 7-12.

9. Chikhani L, Dichamp J (2003) Bruxism, tempromandibular dysfunction and botulinum toxin. Ann Readapt Med Phys 46: 333-337.

10. Defazio G, Abbruzzese G, Girlanda P, Vacca L, Currà A, et al. (2002) Botulinum Toxin A Treatment for Primary Hemifacial Spasm: a 10-year multicenter study. Arch Neurol 59:418-420.
11. Freund B, Schwartz M, Symington JM (2000) Botulinum toxin: new treatment for tempromandibular disorders. Br J Oral Maxillofac Surg 38: 466-471.

12. Yoshida K, lizuka T (2006) Botulinum toxin treatment for upper airway collapse resulting from tempromandibular joint dislocation due to jaw-opening dystonia Cranio 24: 217-222.

13. Song PC, Schwartz J, Blitzer A (2007) The emerging role of botulinum toxin in the treatment of temporomandibular disorders. Oral Dis13: 253-260.

14. Jankovic J (2009) Disease-oriented approach to botulinum toxin use. Toxicon 54: 614-623.

15. Dowson AJ, Kilminster SG, Salt R (2008) Clinical profile of botulinum toxin A in patients with chronic headaches and cervical dystonia: a prospective, openlabel, longitudinal study conducted in a naturalistic clinical practice setting Drugs R D 9: 147-158

16. Makki A, Susan R (2008) Orofacial Pain and Neurological Disorders Affecting the Head and Neck. Improving Oral Health for the Elderly 17: 369-392.

17. Balasubramaniam R, Rasmussen J, Carlson LW, Van Sickels JE, Okeson JP (2008) Oromandibular dystonia revisited: a review and a unique case. J Ora Maxillofac Surg 66: 379-386.

18. Bakke M, Møller E, Werdelin LM, Dalager T, Kitai N, et al. (2005) Treatment of severe tempromandibular joint clicking with botulinum toxin in the latera pterygoid muscles in two cases of anterior disc displacement. Oral Surg Oral Med Oral Pathol Oral Radiol Endod 100: 693-700.

19. National Institute of dental and craniofacial research. (2008).

20. Binder WJ, Brin MF, Blitzer A, Schoenrock LD, Pogoda JM (2000) Botulinum toxin type A (BOTOX) for treatment of migraine headaches: an open-label study. Otolaryngol Head Neck Surg 123: 669-676.

21. Hoque A, McAndrew M (2009) Use of botulinum toxin in dentistry. N Y State Dent J 75: 52-55. 